\title{
Gender Expression Associated with BMI in a Prospective Cohort Study of US Adolescents
}

\author{
S. Bryn Austin ${ }^{1,2,3}$, Najat J. Ziyadeh ${ }^{1}$, Jerel P. Calzo ${ }^{1}$, Kendrin R. Sonneville ${ }^{4}$, Grace A. Kennedy ${ }^{1}$, \\ Andrea L. Roberts ${ }^{3}$, Jess Haines ${ }^{5}$, and Emily A. Scherer ${ }^{6}$
}

Objective: To examine the relationship between gender expression (GE) and BMI in adolescence.

Methods: Repeated measures of weight-related behaviors and BMI were collected from 1996 to 2011 via annual/biennial self-report surveys from youth aged 10 to 23 years (6,693 females, 2,978 males) in the longitudinal Growing Up Today Study. GE (very conforming [referent], mostly conforming, nonconforming) was assessed in 2010/11. Sex-stratified, multivariable linear models estimated GE group differences in $\mathrm{BMI}$ and the contribution of sexual orientation and weight-related exposures to group differences. Models for males included interaction terms for GE with age.

Results: In females, mostly conforming youth had $0.53 \mathrm{~kg} \mathrm{~m}^{-2}$ and nonconforming had $1.23 \mathrm{~kg} \mathrm{~m}^{-2}$ higher BMI; when adding adjustment for sexual orientation and weight-related exposures, GE group estimates were attenuated up to $8 \%$ and remained statistically significant. In males, mostly conforming youth had $-0.67 \mathrm{~kg} \mathrm{~m}^{-2}$ and nonconforming had $-1.99 \mathrm{~kg} \mathrm{~m}^{-2}$ lower BMl (age [in years]) interactions were between -0.09 and $-0.14 \mathrm{~kg} \mathrm{~m}^{-2}$; when adding adjustment for sexual orientation and weight-related exposures, GE group estimates were attenuated up to $11 \%$ and remained statistically significant.

Conclusions: GE is a strong independent predictor of BMI in adolescence. Obesity prevention and treatment interventions with youth must address ways that gender norms may reinforce or undermine healthful behaviors.

Obesity (2016) 24, 506-515. doi:10.1002/oby.21338

\section{Introduction}

US societal norms of masculinity and femininity pattern health behaviors of high public health importance, and dominant cultural standards for appearance strongly link femininity with thinness (1) and masculinity to physical stature and muscularity (2). Findings from numerous studies suggest powerful effects of these gendered cultural standards on weight- and shape-related health indicators in adolescents and adults. A longitudinal study of adolescents found that weight concerns among girls increased from age 11 to 16 years, following the physical changes of puberty (3). In another study, excess prevalence of depressive symptoms in adolescent girls compared to boys was found to be partially mediated by perceived overweight status, a gendered weight concern more common in girls than boys, regardless of actual overweight (4). Previous research has identified clear gender differences in efforts at weight control and weight-related behaviors. For instance, adolescent girls have been found to be more likely than boys to restrict their diets (54\% girls, $24 \%$ boys), use diet products ( $10 \%$ girls, $4 \%$ boys), purge ( $8 \%$ girls, $3 \%$ boys), and engage in weight-controlmotivated exercising (67\% girls, $47 \%$ boys) (5). In line with societal masculinity norms, men who endorse high levels of drive for muscularity also express high desire to gain weight in muscle (6), and, unlike adolescent girls, boys report elevated body dissatisfaction at low body mass index (BMI) $(7,8)$.

Previous research in other health domains has found differences by gender expression - that is, the degree to which one presents oneself in a way consistent with culturally defined expressions of masculine or feminine-in problem drinking (9) and violence perpetration (10). Gender expression also patterns cancer risk behaviors (11), including cigar smoking and UV tanning bed use, such that more masculine males are more likely than other males to smoke cigars and more feminine females are more likely than other females to engage in UV tanning.

\footnotetext{
${ }^{1}$ Division of Adolescent and Young Adult Medicine, Boston Children's Hospital, Boston, Massachusetts, USA. Correspondence: S. Bryn Austin (bryn.austin@childrens.harvard.edu) ${ }^{2}$ Channing Division of Network Medicine, Brigham and Women's Hospital and Harvard Medical School, Boston, Massachusetts, USA ${ }^{3}$ Department of Social and Behavioral Sciences, Harvard T.H. Chan School of Public Health, Boston, Massachusetts, USA

${ }^{4}$ Department of Nutritional Sciences, University of Michigan School of Public Health, Ann Arbor, Michigan, USA ${ }^{5}$ Department of Family Relations and Applied Nutrition, University of Guelph, Guelph, Ontario, Canada ${ }^{6}$ Department of Biomedical Data Science, Geisel School of Medicine at Dartmouth, Hanover, New Hampshire.
}

Funding agencies: This study was funded by grant HD066963 from the National Institutes of Health. S.B. Austin is supported by the Leadership Education in Adolescent Health project, Maternal and Child Health Bureau, Health Resources and Services Administration grant 6T71-MC00009. J.P. Calzo is supported by grant K01 DA034753 from the National Institutes of Health. 
No research to the authors' knowledge has directly explored the association of gender expression with BMI $\mathrm{kg} \mathrm{m}^{-2}$ ) within the sexes in adolescence, though previous studies have documented differences in weight-related health behaviors by gender expression within the sexes. For instance, in the Growing Up Today Study (GUTS), a national cohort of US youth, researchers found that gender conforming girls were more likely to endorse trying to look like people in the media than gender nonconforming girls, and gender conforming boys were found to be more sports involved than gender nonconforming boys $(11,12)$. Because thinness is not consistent with dominant cultural standards of masculinity, youth who conform to masculinity norms may be more likely than other youth to engage in obesogenic behaviors, such as fast food consumption (13), overeating (14), and sedentary behaviors (e.g., TV viewing/sedentary screen time) (15).

While gender expression and sexual orientation are distinct constructs, it is important to note that the association between gender expression and sexual orientation is well documented (16), including in the GUTS cohort (17). In GUTS, sexual minorities (e.g., lesbians, gay men, bisexuals) have been found to be more likely than their heterosexual peers to be gender nonconforming. In addition, sexual orientation disparities in BMI have been found in youth, where lesbian and bisexual females have higher BMI and gay males lower BMI than heterosexual peers (18-20). Prospective research has found in adolescent males that heterosexuals experience greater BMI gains over time than gay males, leading to wider disparities in BMI by young adulthood than earlier in adolescence (19). Whether gender expression may have an association with BMI independent of sexual orientation is not known.

Other exposures known to be associated with higher risk of overweight remain underexplored as to how they may be associated with gender expression. These include exposures such as mother's BMI in childhood, family household annual income, infrequent family dinners, skipping breakfast, fast food consumption, overeating or binge eating, excessive or insufficient sleep at night, sugarsweetened beverage consumption, and TV viewing (21).

Given the evidence that societal norms of masculinity and femininity may pattern weight-related behaviors in adolescents, gender expression also may be associated with BMI and BMI gain throughout adolescence. Understanding the potential relationship between gender expression and BMI is critical, as obesity in adolescence confers a strong likelihood of persisting into adulthood and is associated with a myriad of negative health outcomes (22). In the current study, we assessed the relationship between gender expression and BMI across adolescence and into early adulthood in the GUTS cohort. We hypothesized that in adolescence, higher gender nonconformity in girls (i.e., more masculine) and higher gender conformity in boys (also more masculine) would be associated with a higher BMI and greater BMI gains over time compared to same-sex peers.

\section{Methods}

\section{Sample}

Data were collected from 1996 to 2011 via annual and biennial selfreport surveys from adolescents participating in the longitudinal GUTS cohort, which is composed of a GUTS1 cohort $(n=16,882)$ begun in 1996 and a GUTS2 cohort $(n=10,442)$ begun in 2004. At baseline for each cohort, participants were between the ages of 9-15 years and were invited to participate if their mother was enrolled in the Nurses' Health Study 2 cohort (http://www.channing.harvard. edu/nhs/?page_id=70). Once parental consent was obtained, participants who returned a completed questionnaire at baseline were considered enrolled. The cohort is $94 \%$ of white race/ethnicity. This study has been approved by the Brigham and Women's Hospital Institutional Review Board.

\section{Measures}

Socially assigned gender expression was the primary predictor and was assessed in 2010-11 with a brief, validated, two-item self-report measure of how others perceive one's gendered appearance and mannerisms $(23,24)$. The construct "socially assigned" refers to how one believes one is perceived by others. The measure was based on one previously developed by the Centers for Disease Control and Prevention to assess socially assigned race (25). Participants were asked to rate how they believe others would describe their "appearance, style, or dress" and "mannerisms" each on a 7-point Likert-scale $(1=$ very feminine; $7=$ very masculine $)$. In previous research with the GUTS cohort, the scale items were highly correlated (Pearson $r=0.68 ; P<0.0001$ ) (26). A gender conformity score was created by taking the mean response of the two items and reverse coding for males so that a higher score indicated more gender nonconformity. A mean score of $<1.5$ was categorized as very gender conforming, a score from 1.5 to 3 inclusive as mostly gender conforming, and a score higher than 3 as gender nonconforming. A participant's socially assigned gender expression was considered to be constant over all observations (time-invariant), and the very gender conforming group served as the referent.

BMI was the outcome and was calculated from repeated measures of height and weight, assessed via annual or biennial self-reports from 1996 to 2011 and treated as a continuous measure in $\mathrm{kg} \mathrm{m}^{-2}$ units. Self-reported heights and weights have been found to generate valid estimates of BMI cross-sectionally (27) and of BMI change longitudinally (28) in youth.

Sexual orientation was assessed in multiple waves and included in analyses as a predictor of BMI using sexual orientation reported in the same year as the wave in which BMI was assessed when available. When sexual orientation was not collected in a year BMI was reported, it was back assigned from the next available wave. It was assessed using a single item (29), which asked participants to select "which of the follow best describes your feelings? (1) completely heterosexual (attracted to persons of the same sex), (2) mostly heterosexual, (3) bisexual (equally attracted to men and women), (4) mostly homosexual, (5) completely homosexual (gay/lesbian, attracted to persons of the same sex), (6) not sure." Because of small subsample sizes, responses of "mostly homosexual" and "completely homosexual" were combined to create a "lesbian/gay" category. Responses of "not sure" were treated as missing for the wave in which "not sure" was reported.

Weight-related behaviors were assessed with validated measures. Self-report measures assessed behavior over the past year and included physical activity (hours per week in moderate/vigorous activity; ordinal, seven levels ranging from 0 to 11 or more hours), TV viewing (hours per week viewing TV; ordinal, eight levels ranging from 0 to 18 or more hours), hours of sleep per night (hours 
TABLE 1 Sample characteristics at age 17 years among female and male youth in the Growing Up Today Study $(N=6,649)$

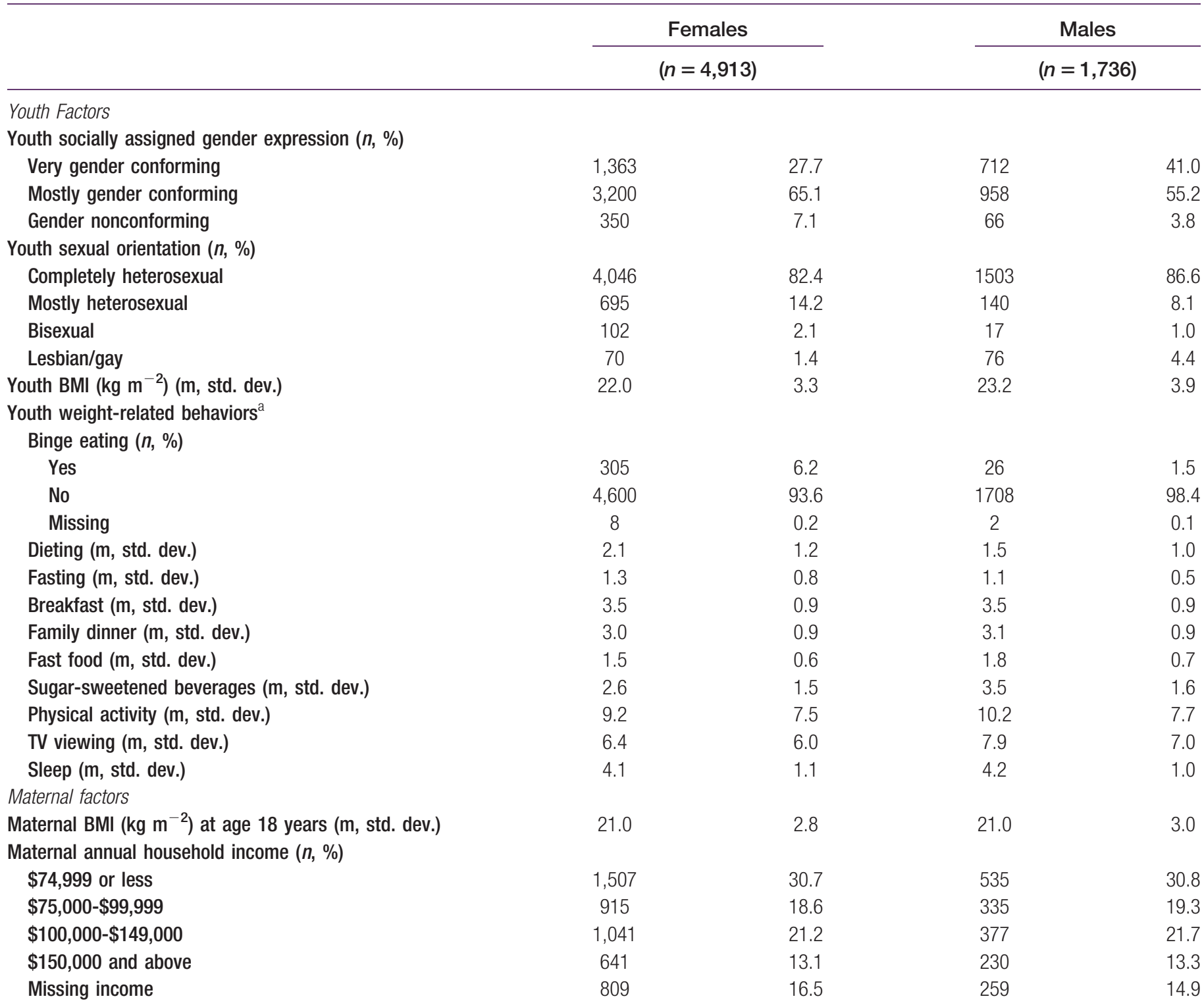

aYouth weight-related behaviors: binge eating (binary, any binge eating in the past year); dieting (ordinal, five levels ranging from never to always); fasting (ordinal, five levels

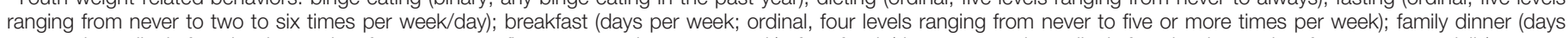

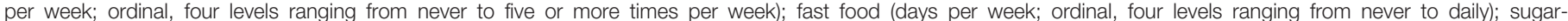
sweetened beverages (servings per day; ordinal, seven levels ranging from never/less than once per month to three or more servings per day); physical activity (hours per

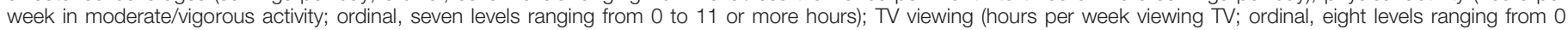
to 18 or more hours); sleep (hours sleep per night; ordinal, eight levels ranging from $<5$ to 11 or more hours).

sleep per night; ordinal, eight levels ranging from $<5$ to 11 or more hours), sugar-sweetened beverage consumption (servings per day; ordinal, seven levels ranging from never/less than once per month to three or more servings per day), fast food consumption (days per week; ordinal, four levels ranging from never to daily), eating breakfast (days per week; ordinal, four levels ranging from never to 5 or more times per week), eating dinner with family (days per week; ordinal, four levels ranging from never to 5 or more times per week), dieting (ordinal, five levels ranging from never to always), binge eating (binary, any binge eating in the past year), and fasting to control weight (ordinal, five levels ranging from never to two to six times per week/day). Weight-related behavioral variables were included in analyses as lagged predictors of BMI using values reported 1 year prior to the wave when BMI was reported when available. When a weight-related behavior was not collected in the year prior to when BMI was reported, it was carried forward or backward from the closest available wave.

Covariates included youth age (range 10-23 years), race/ethnicity, gender (female/male), and membership in the GUTS 1 or GUTS 2 cohort, in addition to mother's annual household income in 2001 (ordinal, four levels ranging from less than $\$ 75,000$ to $\$ 150,000$ and above) and mother's BMI at age 18 years (continuous), both reported by the participant's mother. 
TABLE 2 Sample characteristics at age 17 years among female youth, by socially assigned gender expression, in the Growing Up Today Study $(N=4,913)$

\begin{tabular}{|c|c|c|c|c|c|c|c|}
\hline & $\begin{array}{l}\text { Very } \\
\text { con }\end{array}$ & & $\begin{array}{r}\text { Most } \\
\text { cor }\end{array}$ & ider & nonc & ming & \\
\hline & $(n=$ & & $(n$ & & & & $P$ value \\
\hline Youth factors & & & & & & & \\
\hline Sexual orientation $(n, \%)$ & & & & & & & \\
\hline Completely heterosexual & 1,258 & 92.3 & 2,578 & 80.6 & 210 & 60.0 & $<0.0001^{\mathrm{a}}$ \\
\hline Lesbian & 5 & 0.4 & 37 & 1.2 & 28 & 8.0 & \\
\hline $\begin{array}{l}\text { BMI }\left(\mathrm{kg} \mathrm{m}^{-2}\right) \text { at age } 17 \text { years (m, std. dev.) } \\
\text { Youth weight-related behaviors }{ }^{\text {b }}\end{array}$ & 21.3 & 2.9 & 22.2 & 3.4 & 23.3 & 3.7 & $<0.0001$ \\
\hline Binge eating $(n, \%)$ & & & & & & & \\
\hline Yes & 73 & 5.4 & 202 & 6.3 & 30 & 8.6 & 0.0485 \\
\hline Fasting (m, std. dev.) & 1.3 & 0.8 & 1.3 & 0.7 & 1.4 & 0.9 & 0.6940 \\
\hline Breakfast (m, std. dev.) & 3.5 & 0.9 & 3.5 & 0.9 & 3.3 & 1.0 & 0.1269 \\
\hline Family dinner (m, std. dev.) & 3.0 & 0.9 & 3.0 & 0.9 & 2.8 & 1.0 & 0.0960 \\
\hline Fast food (m, std. dev.) & 1.5 & 0.6 & 1.5 & 0.6 & 1.5 & 0.7 & 0.3053 \\
\hline Sugar-sweetened beverages (m, std. dev.) & 2.5 & 1.4 & 2.6 & 1.5 & 2.7 & 1.6 & 0.0667 \\
\hline Physical activity (m, std. dev.) & 9.4 & 7.5 & 9.0 & 7.4 & 9.7 & 8.4 & 0.9752 \\
\hline TV viewing (m, std. dev.) & 6.2 & 5.9 & 6.4 & 6.0 & 6.9 & 6.1 & 0.2960 \\
\hline Sleep (m, std. dev.) & 4.1 & 1.1 & 4.1 & 1.1 & 3.9 & 1.3 & 0.4761 \\
\hline Maternal factors & & & & & & & \\
\hline BMI $\left(\mathrm{kg} \mathrm{m}^{-2}\right)$ at Age 18 years (m, std. dev.) & 20.8 & 2.7 & 21.0 & 2.8 & 21.6 & 3.1 & 0.0020 \\
\hline
\end{tabular}

aBold indicates statistical significance at $P<0.05$.

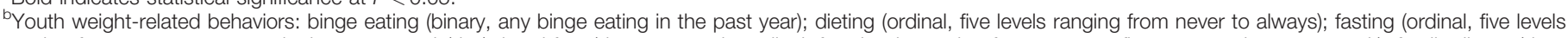

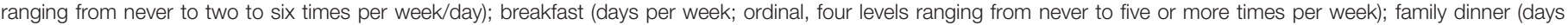
per week; ordinal, four levels ranging from never to five or more times per week); fast food (days per week; ordinal, four levels ranging from never to daily); sugarsweetened beverages (servings per day; ordinal, seven levels ranging from never/less than once per month to three or more servings per day); physical activity (hours per

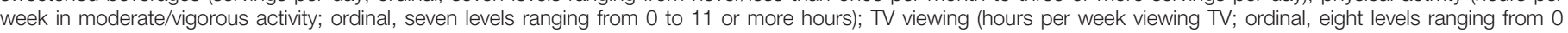
to 18 or more hours); sleep (hours sleep per night; ordinal, eight levels ranging from less than 5 to 11 or more hours).

\section{Statistical analysis: All-available-observations analysis using single imputation of predictors and covariates}

To estimate the association between gender expression and BMI across all waves, the dataset was first converted from a person-level data file to a longitudinal data file whereby each participant contributed an observation each time they completed each questionnaire. All observations with available BMI and predictors were included in the analysis. Missing values of the predictors and covariates were singly imputed to reduce potential bias introduced by nonresponse. We used single imputation for missing covariate data based on last observation carried forward or subsequent value carried back.
Among females, for those who were pregnant at the time BMI was reported or within the past year $(n$ observations $=971)$, their BMI value was set to missing for that wave only, and they were retained in analyses for all other waves in which they provided data. Implausible values on weight, height, or BMI were also set to missing ( $n$ observations $=60$ ).

Multivariable linear generalized estimating equations (GEE) were used to examine differences in BMI across gender expression groups, adjusting for effects of covariates, sexual orientation, and weight-related behaviors. The GEE models account for repeated measures within individuals. Because GUTS participants are all 
TABLE 3 Sample characteristics at age 17 years among male youth, by socially assigned gender expression, in the Growing Up Today Study $(N=1,736)$

\begin{tabular}{|c|c|c|c|c|c|c|c|}
\hline & & $\begin{array}{l}\text { Ider } \\
\text { ing }\end{array}$ & $\begin{array}{r}\text { Mos } \\
\text { cor } \\
\end{array}$ & $\begin{array}{l}\text { nder } \\
\text { ing }\end{array}$ & nonc & $\begin{array}{l}r \\
\text { ming } \\
\end{array}$ & \\
\hline & & & & & & & $P$ value \\
\hline Sexual orientation $(n, \%)$ & & & & & & & \\
\hline Completely heterosexual & 681 & 95.7 & 787 & 82.2 & 35 & 53.0 & $<0.0001^{\mathrm{a}}$ \\
\hline Mostly heterosexual & 26 & 3.7 & 105 & 11.0 & 9 & 13.6 & \\
\hline Bisexual & 0 & 0.0 & 15 & 1.6 & 2 & 3.0 & \\
\hline Gay & 5 & 0.7 & 51 & 5.3 & 20 & 30.3 & \\
\hline BMI $\left(\mathrm{kg} \mathrm{m}^{-2}\right)$ at age 17 years (m, std. dev.) & 23.7 & 4.1 & 23.0 & 3.7 & 22.8 & 4.1 & 0.1012 \\
\hline Youth weight-related behaviors ${ }^{\mathrm{b}}$ & & & & & & & \\
\hline Binge eating $(n, \%)$ & & & & & & & \\
\hline Yes & 5 & 0.7 & 15 & 1.6 & 6 & 9.1 & 0.0024 \\
\hline No & 707 & 99.3 & 942 & 98.3 & 59 & 89.4 & \\
\hline Missing & 0 & 0.0 & 1 & 0.1 & 1 & 1.5 & \\
\hline Dieting (m, std. dev.) & 1.5 & 1.0 & 1.5 & 1.0 & 1.7 & 1.2 & 0.9803 \\
\hline Fasting (m, std. dev.) & 1.1 & 0.4 & 1.1 & 0.6 & 1.4 & 0.9 & 0.0144 \\
\hline Breakfast (m, std. dev.) & 3.5 & 0.9 & 3.5 & 0.9 & 3.1 & 1.0 & 0.0962 \\
\hline Family dinner ( $m$, std. dev.) & 3.1 & 0.8 & 3.0 & 0.9 & 2.9 & 1.0 & 0.0178 \\
\hline Fast food (m, std. dev.) & 1.8 & 0.8 & 1.8 & 0.7 & 1.6 & 0.6 & 0.1618 \\
\hline Sugar-sweetened beverages ( $m$, std. dev.) & 3.7 & 1.5 & 3.5 & 1.6 & 3.3 & 1.8 & 0.0002 \\
\hline Physical activity (m, std. dev.) & 11.5 & 7.8 & 9.4 & 7.6 & 7.4 & 6.9 & $<0.0001$ \\
\hline TV viewing (m, std. dev.) & 8.2 & 7.1 & 7.7 & 6.9 & 6.8 & 6.8 & 0.0435 \\
\hline Sleep (m, std. dev.) & 4.3 & 1.0 & 4.1 & 1.1 & 4.0 & 1.3 & 0.0010 \\
\hline Maternal factors & & & & & & & \\
\hline BMI $\left(\mathrm{kg} \mathrm{m}^{-2}\right)$ at age 18 years (m, std. dev.) & 20.9 & 2.8 & 21.1 & 3.0 & 21.8 & 4.5 & 0.1395 \\
\hline Annual household income $(n, \%)$ & & & & & & & \\
\hline$\$ 74,999$ or less & 235 & 33.0 & 280 & 29.2 & 20 & 30.3 & \\
\hline$\$ 75,000-\$ 99,999$ & 151 & 21.2 & 173 & 18.1 & 11 & 16.7 & \\
\hline$\$ 100,000-\$ 149,000$ & 141 & 19.8 & 219 & 22.9 & 17 & 25.8 & 0.0891 \\
\hline$\$ 150,000$ and above & 80 & 11.2 & 145 & 15.1 & 5 & 7.6 & \\
\hline Missing income & 105 & 14.8 & 141 & 14.7 & 13 & 19.7 & \\
\hline
\end{tabular}

aBold indicates statistical significance at $P<0.05$.

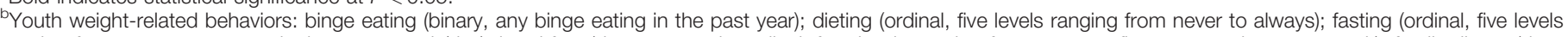

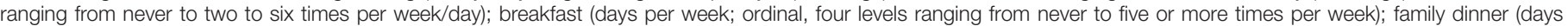
per week; ordinal, four levels ranging from never to five or more times per week); fast food (days per week; ordinal, four levels ranging from never to daily); sugar-

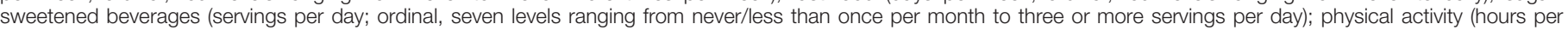

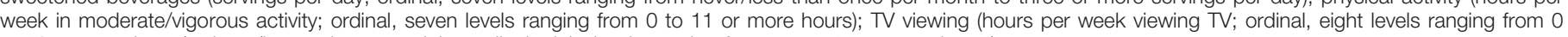
to 18 or more hours); sleep (hours sleep per night; ordinal, eight levels ranging from <5 to 11 or more hours).

children of women in the Nurses' Health Study 2 cohort, the GEE models also account for intracluster correlation resulting from sibling groups in the cohort using the mother's ID (30). An exchangeable residual covariance structure was used for all models. Separate models were examined for females and males. Both age-by-gender expression and age-by-sexual orientation interactions were tested and retained if significant. Among females, age interactions were not significant so were not retained. For males, interactions of age with gender expression and sexual orientation were significant so were retained.

For both females and males, a base model (adjusting for youth age, race/ethnicity, and GUTS cohort and mother's annual household income and mother's BMI at age 18 years), a model additionally adjusting for sexual orientation, and a model additionally adjusting for weight-related behaviors were fit. Weight-related behavioral predictors were retained in models only if they achieved statistical significance at $P<0.05$; therefore, weight-related behavioral predictors retained in the model for females varied from those retained in the model for males. The final all-available-observations analysis sample included 6,693 females and 2,978 males ages 10-23 years, providing 29,406 and 12,516 observations, respectively. All analyses were conducted using SAS 9.3 (Cary, NC).

\section{Missing data analysis and multiple imputation}

To identify differences in participants included in the analyses described above compared to those excluded, we compared the two 
TABLE 4 Adjusted GEE linear models ${ }^{a}$ estimating socially assigned gender expression group differences in BMI $\left(\mathrm{kg} \mathrm{m}^{-2}\right)$ using lagged predictors and repeated measures from 1996 to 2011 among female adolescents and young adults in the Growing Up Today Study 1 and 2

\begin{tabular}{|c|c|c|c|}
\hline \multirow[b]{2}{*}{ Predictors } & \multicolumn{3}{|c|}{ Females } \\
\hline & $\begin{array}{c}\text { Base model, } \\
\text { B (95\% Cl) }\end{array}$ & $\begin{array}{l}\text { Model adjusted for } \\
\text { sexual orientation, } \\
\text { B }(95 \% \mathrm{Cl})\end{array}$ & $\begin{array}{c}\text { Model adjusted for } \\
\text { weight-related behaviors, } \\
\text { B }(95 \% \mathrm{Cl})\end{array}$ \\
\hline Mostly gender conforming & $0.53(0.28,0.78)$ & $0.51(0.25,0.76)$ & $0.52(0.27,0.77)$ \\
\hline Gender nonconforming & $1.23(0.74,1.73)$ & $1.17(0.65,1.68)$ & $1.13(0.64,1.62)$ \\
\hline \multicolumn{4}{|l|}{ Age } \\
\hline Age & $0.47(0.46,0.48)$ & $0.47(0.46,0.48)$ & $0.47(0.46,0.48)$ \\
\hline Age squared & $-0.03(-0.03,-0.02)$ & $-0.03(-0.03,-0.02)$ & $-0.03(-0.03,-0.02)$ \\
\hline Lesbian & & $0.67(-0.13,1.47)$ & $0.65(-0.15,1.44)$ \\
\hline \multicolumn{4}{|l|}{ Weight-related behaviors } \\
\hline Dieting & & & $0.24(0.20,0.28)$ \\
\hline Fasting & & & $-0.09(-0.16,-0.02)$ \\
\hline Breakfast & & & $-0.16(-0.23,-0.09)$ \\
\hline Fast food & & & $0.07(0.01,0.14)$ \\
\hline Physical activity & & & $-0.01(-0.02,-0.01)$ \\
\hline TV viewing & & & $0.02(0.01,0.02)$ \\
\hline
\end{tabular}

AAll models control for GUTS cohort, race/ethnicity, mother's income, and mother's BMl at 18 years of age. Bolding indicates statistical significance at $P<0.05$.

groups (those with no observations for BMI and predictors vs. those with BMI and predictors for at least some observations) in terms of gender, age, race/ethnicity, cohort, sexual orientation, and socially assigned gender expression. There were no differences between those included in analyses and those excluded in race/ethnicity $(P=0.99)$, and within the GUTS1 cohort, no differences in sexual orientation $(P=0.40)$ were observed; though in the GUTS2 cohort, mostly heterosexual and lesbian/gay participants were more likely to be included in analyses than other orientation groups $(P<0.0001)$. In addition, greater likelihood of being included in analyses was associated with: female vs. male gender $(P<0.0001)$, GUTS1 vs. GUTS2 cohort membership $(P<0.0001)$, older compared to younger age at baseline $(P<0.0001)$, and being mostly gender conforming compared to the other two gender expression groups $(P<0.01)$.

To explore potential bias due to missing values that could result from all-available-observations analysis, we carried out secondary analyses using multiple imputation (MI) (31). The MI models for females and males included all predictor variables of the final multivariable models described above with the exception of socially assigned gender expression (the primary predictor). The regression equations were applied iteratively to produce multiple, newly created, complete datasets with all of the missing values filled in. The next phase of MI involved analyzing these multiple, newly generated datasets, and the last phase combined the model estimates created from each dataset into one set of estimates. There were few differences in findings comparing MI models to all-availableobservations analysis models and no important differences in direction or significance of associations; therefore, tables and figures present results based on all-available-observations analyses.

\section{Results}

Table 1 presents sample characteristics at age 17 years, which falls midway in the age range included in analyses (10-23 years); 4,913 females and 1,736 males provided data at age 17 years presented in the table. Among 17-year-old females and males, respectively, 28\% $(n=1,363)$ and $41 \%(n=712)$ were very gender conforming, $65 \%(n=3,200)$ and $55 \%(n=958)$ were mostly gender conforming, and 7\% $(n=350)$ and $4 \%(n=66)$ were gender nonconforming. For females, mean BMI at age 17 years was $22.0 \mathrm{~kg} \mathrm{~m}^{-2}$ (std. dev. 3.3), and for males, mean BMI at age 17 years was $23.2 \mathrm{~kg} \mathrm{~m}^{-2}$ (std. dev. 3.9).

Table 2 displays maternal and youth factors and youth BMI at age 17 years by gender expression among females. Differences at age 17 years across gender expression groups were found for maternal BMI at age 18 years and youth factors, including sexual orientation, binge eating, and dieting $(P \mathrm{~s}<0.05)$. Also among females, at age 17 
TABLE 5 Adjusted GEE linear models ${ }^{a}$ estimating socially assigned gender expression group differences in BMl $\left(\mathrm{kg} \mathrm{m}^{-2}\right)$ using lagged predictors and repeated measures from 1996 to 2011 among male adolescents and young adults in the Growing Up Today Study 1 and 2

\begin{tabular}{|c|c|c|c|}
\hline \multirow[b]{3}{*}{ Predictors } & \multicolumn{3}{|c|}{ Males } \\
\hline & \multicolumn{3}{|c|}{$\#$ observations $=12,516$} \\
\hline & $\begin{array}{c}\text { Base model, } \\
\text { B }(95 \% \mathrm{Cl})\end{array}$ & $\begin{array}{c}\text { Model adjusted } \\
\text { for sexual orientation, } \\
\text { B }(95 \% \mathrm{Cl})\end{array}$ & $\begin{array}{c}\text { Model adjusted for } \\
\text { weight-related behaviors, } \\
\text { B }(95 \% \mathrm{Cl})\end{array}$ \\
\hline Mostly gender conforming & $-0.67(-1.09,-0.25)$ & $-0.64(-1.06,-0.22)$ & $-0.63(-1.03,-0.22)$ \\
\hline Gender nonconforming & $-1.99(-2.76,-1.21)$ & $-1.88(-2.75,-1.01)$ & $-1.78(-2.63,-0.93)$ \\
\hline \multicolumn{4}{|l|}{ Age } \\
\hline Age & $0.64(0.61,0.67)$ & $0.65(0.62,0.68)$ & $0.65(0.62,0.68)$ \\
\hline Age squared & $-0.02(-0.03,-0.02)$ & $-0.02(-0.03,-0.02)$ & $-0.02(-0.03,-0.02)$ \\
\hline \multicolumn{4}{|l|}{ Sexual orientation } \\
\hline Completely heterosexual & & Reference & Reference \\
\hline Mostly heterosexual & & $-0.43(-1.10,0.24)$ & $-0.41(-1.04,0.23)$ \\
\hline Bisexual & & $0.95(-1.43,3.32)$ & $0.90(-1.41,3.20)$ \\
\hline Gay & & $-0.29(-1.73,1.16)$ & $-0.44(-1.82,0.94)$ \\
\hline \multicolumn{4}{|l|}{ Interactions: Orientation-by-age } \\
\hline Mostly heterosexual-by-age & & $-0.04(-0.11,0.02)$ & $-0.04(-0.11,0.03)$ \\
\hline Bisexual-by-age & & $-0.04(-0.21,0.12)$ & $-0.03(-0.19,0.12)$ \\
\hline Gay-by-age & & $-0.25(-0.36,-0.14)$ & $-0.24(-0.34,-0.13)$ \\
\hline \multicolumn{4}{|l|}{ Weight-related behaviors } \\
\hline
\end{tabular}

aAll models control for GUTS cohort, race/ethnicity, mother's income, and mother's BMl at 18 years of age. Bolding indicates statistical significance at $P<0.05$.

years, gender conformity was associated with lower BMI: very gender conforming BMI $21.3 \mathrm{~kg} \mathrm{~m}^{-2}$ (std. dev. 2.9); mostly gender conforming BMI $22.2 \mathrm{~kg} \mathrm{~m}^{-2}$ (std. dev. 3.4); gender nonconforming BMI $23.3 \mathrm{~kg} \mathrm{~m}^{-2}$ (std. dev. 3.7) $(P<0.0001)$.

Table 3 displays maternal and youth factors and youth BMI at age 17 years by gender expression among males. Differences at age 17 years across gender expression groups were found for several youth factors, including sexual orientation, binge eating, fasting, family dinner, sugar-sweetened beverages, physical activity, television viewing, and sleep $(P \mathrm{~s}<0.05)$. However, among males, gender conformity was not associated with BMI at age 17 years: Very gender conforming BMI $23.7 \mathrm{~kg} \mathrm{~m}^{-2}$ (std. dev. 4.1); mostly gender conforming BMI $23.0 \mathrm{~kg} \mathrm{~m}^{-2}$ (std. dev. 3.7); gender nonconforming BMI $22.8 \mathrm{~kg} \mathrm{~m}^{-2}$ (std. dev. 4.1) $(P=0.10)$.

Tables 4 and 5 present the multivariable GEE model results for 6,693 females $(n$ observations $=2$ 9,406 $)$ and 2,978 males $(n$ observations $=$
12,516), respectively, from ages 10-23 years. Figures 1 and 2 display predicted mean BMI $\left(\mathrm{kg} \mathrm{m}^{-2}\right)$ by age and gender expression for females and males, respectively, as estimated in models presented in Tables 4 and 5. For females, compared to the very gender conforming group, mostly gender conforming expression was associated with 0.53 $\mathrm{kg} \mathrm{m}^{-2}$ higher BMI and gender nonconforming expression was associated with $1.23 \mathrm{~kg} \mathrm{~m}^{-2}$ higher BMI (base model, Table 4). Accounting for sexual orientation and weight-related behaviors resulted in virtually no change in the estimate for the mostly gender conforming group and only $8 \%$ attenuation in the estimate for the gender nonconforming group, and group differences remained statistically significant (Table 4).

As shown in Table 5, for males, compared to the very gender conforming group, mostly gender conforming expression was associated with $-0.67 \mathrm{~kg} \mathrm{~m}^{-2}$ lower BMI with an additional $-0.09 \mathrm{~kg} \mathrm{~m}^{-2}$ reduction in relative BMI with each year of age (base model, Table 5); gender nonconforming expression was associated with -1.99 $\mathrm{kg} \mathrm{m}^{-2}$ lower BMI with an additional $-0.14 \mathrm{~kg} \mathrm{~m}^{-2}$ reduction in 


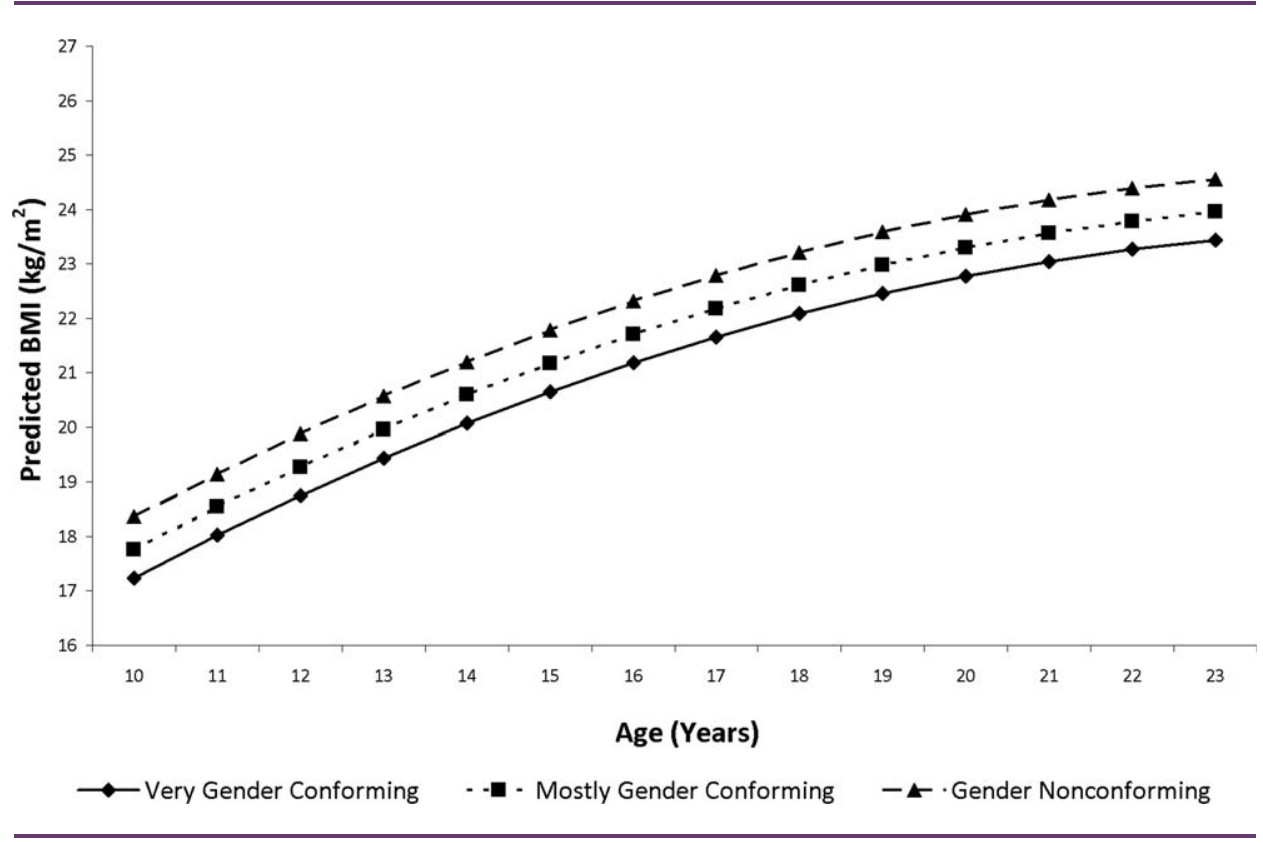

Figure 1 Predicted mean BMl $\left(\mathrm{kg} \mathrm{m}^{-2}\right)$ by age and gender expression group as estimated from model in Table 4 adjusting for sexual orientation and weight-related behaviors, females.

relative BMI with each year of age (base model, Table 5). Accounting for sexual orientation and weight-related behaviors resulted in just $6 \%$ attenuation in the estimate for the mostly gender conforming group and very small attenuation in the gender expression-by-age interaction term, which remained significant. For the gender nonconforming group, accounting for sexual orientation and weight-related behaviors resulted in almost $11 \%$ attenuation of the estimate and the gender expression-by-age interaction was reduced substantially and became nonsignificant (Table 5).

\section{Discussion}

Obesity is a well-established public health priority (21). Furthermore, recent evidence implicates societal pressures on young people to conform to socially accepted expressions of masculinity and femininity in a range of health damaging behaviors (9-11), including weightrelated behaviors $(11,12,32)$. Nevertheless, to our knowledge, this is the first prospective cohort study examining the relationship between gender expression and BMI in adolescence. Our findings indicate that

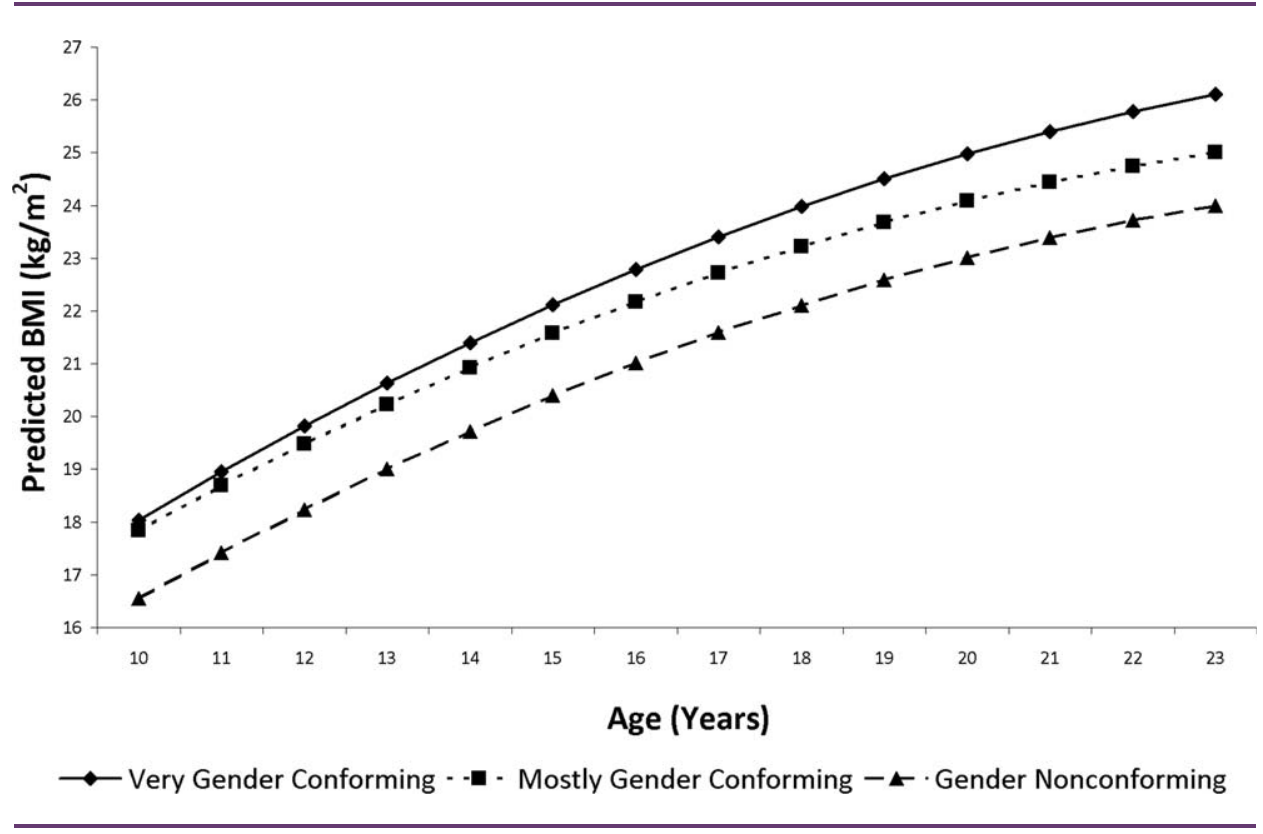

Figure 2 Predicted mean BMl $\left(\mathrm{kg} \mathrm{m}^{-2}\right)$ by age and gender expression group as estimated from model in Table 5 adjusting for sexual orientation and weight-related behaviors, males. 
socially assigned gender expression is a powerful predictor of BMI. In females, nonconformity - or greater masculinity - was linked with higher BMI, though not with greater gains in BMI throughout adolescence. In males, conformity - that is, greater masculinity-was similarly linked with higher BMI as well as with greater BMI gains throughout adolescence. We accounted for a comprehensive set of weight-related behaviors occurring throughout adolescence, in addition to sexual orientation, finding that these exposures explained only $\sim 10 \%$ of gender expression group differences. Thus, gender expression plays a substantial role in BMI in adolescence, but the underlying pathways are only partially illuminated here.

Among children with overweight or obesity at ages 8-15 years, boys are less likely than girls of similar weight status to perceive themselves as overweight or obese (33). Furthermore, among adolescent boys ages 16-22 years, one study found that one in three boys with BMI in the healthy range and one in six boys with BMI in the overweight or obese range reported trying to gain weight (8). Patterns observed in these studies may result in part from variation in gender norms and gender expression both within each sex and between boys and girls. While gender norms and gender expression have not typically been targeted in behavioral interventions for obesity prevention, public health professionals working in other health domains have gained important insights into the modifiability of gender norms and the impact these types of interventions can have on targeted health outcomes. For instance, a recent study reviewed 22 evaluations of sexuality and HIV education curricula, of which 10 specifically targeted gender norms (34). This review found that $80 \%$ of the studies designed to change gender norms to be more equitable resulted in reduction in unintended pregnancy or sexually transmitted infections; whereas, only $17 \%$ of the studies not targeting gender norms had these beneficial health effects. Similarly, preventive interventions targeting gender norms to reduce intimate-partner and dating violence have been successful in reducing violence perpetration by boys and men (35-37). Given the substantial elevation of BMI associated with masculine gender expression in both females and males in the present study, our findings suggest that, as has been done in some other fields of public health, the field of overweight prevention may need to target gender norms relating to weight-related behaviors and perceptions in designing health promoting interventions.

Perhaps most importantly, health professionals, policymakers, and advocates are increasingly targeting structural forces that create and perpetuate harmful gender norms. Globally, a myriad of systemslevel initiatives are being tested to reduce discrimination, violence, and economic inequalities linked to gender, gender expression and identity, and sexual orientation (38-40). These types of upstream strategies are likely to hold the most promise to effect lasting change in gender-expression-related health inequities.

Our study has several limitations. We used a single measure to assess socially assigned gender expression. In addition, in most cases, gender expression was assessed after weight-related behaviors and BMI were assessed. It is possible that for some participants their weight status influenced the way they chose to describe their gender expression. The GUTS cohort is neither racially/ethnically or economically diverse nor representative of the US population, which limits generalizability. Importantly, participants were not recruited into the sample based on their gender expression. While validated measures were used to assess weight-related behavioral predictors, surveys were administered only annually or biennially, so important variation occurring between survey years affecting BMI might be missed.

\section{Conclusion}

In US society, youth are inundated with messages from media, peers, and family about cultural expectations of gender expression for girls and women, boys and men. Evidence is accumulating that these messages carry with them health risks in myriad domains (9$12,32)$. With the present study, it is clear that conformity to masculinity ideals confers risk of elevated BMI in both sexes and, for males in particular, more rapid BMI gains in adolescence. While our study examined a wide range of known predictors of BMI in youth, our results indicated that these exposures accounted for a relatively small proportion of the pronounced gender expression group differences in BMI. Much work remains to identify the specific leptogenic and obesogenic behaviors and exposures that produce substantial gender expression group differences in BMI. In addition, greater health research attention to societal gender norms will be crucial to understanding and mitigating the ways that societal messages idealizing particular expressions of masculinity and femininity are undermining the health and well-being of both girls and boys. $O$

\section{Acknowledgments}

The authors thank the GUTS team of investigators for their contributions to this article and the thousands of young people across the country participating in the Growing Up Today Study.

\section{(C) 2016 The Obesity Society}

\section{References}

1. Bordo S. Unbearable Weight: Feminism, Western Culture and the Body. Berkeley, CA: University of California Press; 1993.

2. Pope H, Phillips KA, Olivardia R. The Adonis complex: The secret crisis of male body obsession. New York: Free. New York: Free Press; 2000.

3. May AL, Kim J-Y, McHale SM, Crouter AC. Parent-adolescent relationships and the development of weight concerns from early to late adolescence. Int J Eat Disord 2006;39:729-740.

4. Vaughan CA, Halpern CT. Gender differences in depressive symptoms during adolescence: the contributions of weight-related concerns and behaviors. J. Res Adolesc 2010;20:389-419.

5. Chao YM, Pisetsky EM, Dierker LC, et al. Ethnic differences in weight control practices among U.S. adolescents from 1995 to 2005. Int J Eat Disord 2008;41:124-133.

6. McCreary DR, Saucier DM, Courtenay WH. The drive for muscularity and masculinity: testing the associations among gender-role traits, behaviors, attitudes, and conflict. Psychol Men Masculinity 2005;6:83-94.

7. Austin SB, Haines J, Veugelers PJ. Body satisfaction and body weight in children: gender differences and socioeconomic determinants. BMC Public Health 2009;9:313-332.

8. Calzo JP, Corliss HL, Blood EA, Field AE, Austin SB. Development of muscularity and weight concerns in heterosexual and sexual minority males. Health Psychol 2013;32:42-51.

9. Williams RJ, Ricciardelli LA. Negative percpetions about self-control and identification with gender-role stereotypes related to binge eating, problem drinking, and to co-morbidity among adolescents. $J$ Adolesc Health 2003;32:66-72.

10. McCauley HL, Tancredi DJ, Silverman JG, et al. Gender-equitable attitudes, bystander behavior and abuse perpetration in a sample of high school male athletes. Am J Public Health 2013;103:1882-1887.

11. Roberts AL, Rosario M, Calzo JP, Corliss HL, Frazier AL, Austin SB. Masculine boys, feminine girls and cancer risk behaviors: an 11-year longitudinal study. J Adolesc Health 2014;55:373-379.

12. Calzo JP, Roberts AL, Corliss HL, Blood EA, Kroshus E, Austin SB. Physical activity disparities in heterosexual and sexual minority youth ages 12-22 years old: roles of childhood gender nonconformity and athletic self-esteem. Ann Behav Med 2014;47:17-27. 
13. Cutler GJ, Flood A, Hannan P, Neumark-Sztainer D. Major patterns of dietary intake in adolescents and their stability over time. J Nutr 2009;139:323-328.

14. Vincent MA, McCabe MP. Gender differences among adolescents in family, and peers influences on body dissatisfaction, weight loss, and binge eating disorders. $J$ Youth Adolesc 2000;29:205-221.

15. Sisson SB, Church TS, Martin CK, et al. Profiles of sedentary behavior in children and adolescents: the US National Health and Nutrition Examination Survey, 20012006. Int J Pediatr Obes 2009;4:353-359.

16. Gordon AR, Meyer IH. Gender nonconformity as a target of prejudice, discrimination, and violence against LGB individuals. J LGBT Health Res 2007;3: 55-71.

17. Roberts AL, Rosario M, Corliss HL, Koenen K, Austin SB. Elevated risk of posttraumatic stress in sexual minority youths: mediation by childhood abuse and gender nonconformity. Am J Public Health 2012;102:1587-1593.

18. Austin SB, Nelson LA, Birkett MA, Calzo JP, Everett B. Eating disorder symptoms and obesity at the intersections of gender, ethnicity and sexual orientation identity in US high school students. Am J Public Health 2013;103:e16-e22.

19. Austin SB, Ziyadeh NJ, Corliss HL, et al. Sexual orientation disparities in weight status in adolescence: findings from a prospective study. Obesity 2009;17:17761782.

20. Katz-Wise SL, Blood E, Milliren CE, et al. Sexual orientation disparities in BMI among US adolescents and young adults in three race/ethnicity groups. $J$ Obes 2014;2014:1-8

21. Institute of Medicine. Preventing Childhood Obesity: Health in the Balance. Washington, DC: National Academy of Sciences; 2004.

22. Singh AS, Mulder C, Twisk JW, van Mechelen W, Chinapaw MJ. Tracking of childhood overweight into adulthood: a systematic review of the literature. Obes Rev 2008;9:474-488.

23. Wylie SA, Corliss HL, Boulanger V, Prokop LA, Austin SB. Socially assigned gender nonconformity: a brief measure for use in surveillance and investigation of health disparities. Sex Roles 2010;63:264-276.

24. Greytak E, Gill A, Conron KJ. Considerations for identifying transgender and other gender minority adolescent on population-based surveys. In: Heyman JL, ed. Best Practices for Asking Questions to Identify Transgender and Other Gender Minority Respondents on Population-based Surveys. Los Angeles: GenIUSS, Williams Institute, University of California-Los Angeles; 2014:29-34.

25. Jones CP, Truman BI, Elam-Evans LD, et al. Using "socially assigned race" to probe white advantages in health status. Ethn Dis 2008;18:496-504.

26. Reisner SL, Conron KJ, Tardiff LA, Jarvi S, Gordon AR, Austin SB. Monitoring the health of transgender and other gender minority populations: validity of natal sex and gender identity survey items in a US national cohort of young adults. BMC Public Health 2014;14:1224.
27. Goodman E, Hinden BR, Khandelwal S. Accuracy of teen and parental reports of obesity and body mass index. Pediatrics 2000;106:52-58.

28. Berkey CS, Colditz GA. Adiposity in adolescents: change in actual BMI works better than change in BMI z score for longitudinal studies. Ann Epidemiol 2007; 17: 44-50.

29. Austin SB, Conron KJ, Patel A, Freedner N. Making sense of sexual orientation measures: findings from a cognitive processing study with adolescents on health survey questions. J LGBT Health Res 2007;3:55-65.

30. Liang K-Y, Zeger SL. Longitudinal data analysis using generalized linear models. Biometrika 1986;73:13-22.

31. Graham JW. Missing data analysis: making it work in the real world. Annu Rev Psychol 2009; 60:549-576.

32. Meyer C, Blissett J, Oldfield C. Sexual orientation and eating psychopathology: the role of masculinity and femininity. Int J Eat Disord 2001;29:314-318.

33. Sarafrazi N, Hughes JP, Borrud L, Burt V, Paulose-Ram R. Perception of Weight Status in US Children and Adolescents Aged 8-15 Years, 2005-2012. Atlanta, GA: Centers for Disease Control and Prevention; 2014.

34. Haberland NA. The case for addressing gender and power in sexuality and HIV education: a comprehensive review of evaluation studies. Int Perspect Sexual Reprod Health 2015;41:31-42.

35. Pulerwitz J, Hui W, Amey J, Scott LM. Changing gender norms and reducing HIV and violence risk among workers and students in China. J Health Commun 2015;20:869878.

36. Miller E, Tancredi DJ, McCauley HL, et al. One-year follow-up of a coachdelivered dating violence prevention program: a cluster randomized controlled trial. Am J Prev Med 2013;45:108-112.

37. Barker G, Ricardo C, Nascimento M, Olukoya A, Santos C. Questioning gender norms with men to improve health outcomes: evidence of impact. Global Public Health 2010;5:539-553.

38. Kollman K, Waites M. The global politics of lesbian, gay, bisexual and transgender human rights: an introduction. Contemporary Politics 2009;15:1-17.

39. Schwartz JP, Lindley LD. Impacting sexism through social justice prevention: implications at the person and environmental levels. J Primary Prevent 2009;30: $27-41$.

40. Sen G, Östlin P, George A. Unequal, unfair, ineffective and inefficient: gender inequity in health: why it exists and how we can change it. World Health Organization Commission on Social Determinants of Health; 2007; URL: Available at: http://cdrwww.who.int/social_determinants/resources/csdh_media/wgekn_final_report_ 07.pdf; Date accessed: Aug. 3, 2015 